\title{
Adsorption of Cadmium Ions onto the Yellow River Sediment
}

\author{
SuI LIANG HUANG* \\ Numerical Simulation Group for Water Environment, College of Environmental Science \\ and Engineering, Nankai University, Tianjin University, Tianjin, 300071, P.R. of China
}

\begin{abstract}
Adsorption of cadmium ions onto Yellow River sediment was studied in a batch reactor. Equilibrium adsorption of cadmium ions onto Yellow River sediment can be well described by the Langmuir adsorption isotherm. In view of common experimental conditions in the batch reactor, a set of equations for describing variations of both the dissolved heavy metal pollutant concentration and the particulate heavy metal pollutant concentrations (the adsorption content of heavy metal pollutant on unit weight of sediment) with time was formulated with the use of an adsorptive reaction kinetic equation of heavy metal pollutant, mass balance equation and corresponding initial conditions. Furthermore, formulae for calculating the equilibrium dissolved heavy metal concentration and the equilibrium particulate heavy metal concentration (the equilibrium adsorption content of heavy metal pollutant on unit weight of sediment) in the batch reactor were obtained. These can be used as tools for further study. It was found that the saturation adsorption content, $b$, constant of adsorption-desorption rate, $k$, and coefficient of adsorption rate, $k_{1}$ (and coefficient of desorption rate $k_{2}$ ), in the adsorptive reaction kinetic equation of the Langmuir type are independent of the suspended sediment concentration. Adsorption contents of heavy metal pollutants on unit weight of sediment (the suspended particulate heavy metal concentration) decreases with increasing suspended sediment concentration and can be well explained by the law of mass conservation. Adsorption capacity, which is defined as adsorption content of heavy metal pollutant by unit volume of (muddy) water, increases with an increase in either the suspended sediment concentration or initial dissolved heavy metal concentration.
\end{abstract}

Key words: water-sediment-pollutant interaction, adsorption, batch reactor

\section{Introduction}

Heavy metals constitute one of the main sources of contaminants in aquatic environments, particularly in developing countries. In sedimentladen rivers, heavy metals that enter into waters tend to be adsorbed onto sediment and conveyed or deposited together with sediment. China is a

*sui_liang_huang@hotmail.com; Present address: National Center for Computational Hydro Science and Engineering, The University of Mississippi, Carrier Hall, Room 102, P.O. Box 1848, Mississippi, 38677-1848 U.S.A. 
developing country with numerous sediment-laden rivers. A study on adsorption/desorption of heavy metal pollutants on/off sediment and the effect of sediment transport on transport-transformation of heavy metal pollutants in natural waters has practical significance.

The adsorption intensity and capacity of metals onto sediment have been studied intensively in batch reactor experiments since the 1970s (Förstner and Wittmann 1981; Horowitz and Elrick 1987; YRWRPRI 1988; Warren and Zimmerman 1994; Horowitz 1995; Lau and Chu 2000). The adsorption rate of heavy metal pollutant onto sediment, however, has seldom been reported (Huang and Wan 1995). As pointed out in the literature, the kinetic adsorption process of heavy metal pollutants onto sediment has been unaccountably ignored (Förstner and Wittmann 1981; Hart 1986; YRWRPRI 1988; Huang and Wan 1995).

As observed and documented in literature (Förstner and Wittmann 1981; Jin and Wang 1986; McKinley and Jenne 1991; Horowitz 1995), the quantity of a metal adsorbed per unit quantity of sediment decreases significantly with increasing mass of sediment per unit volume (the sediment concentration) in batch reactor experiments. Such a phenomenon is called the "solids concentration" effect. However, there are two different explanations about the effect of solids concentration. One is that the solids concentration effect may be explained by experimental procedure, such as the view of adsorption by "non-settling" colloids that remain suspended in the aqueous phase after centrifugation or filtration. The other suggests that the solids concentration effect can not be interpreted as experimental artefact. Several theories were thus developed (McKinley and Jenne 1991; Huang and Wan 1995). No equation has been formulated to date to describe the equilibrium adsorption content of heavy metal pollutant on unit weight of sediment (the equilibrium particulate heavy metal concentration) or equilibrium dissolved heavy metal concentration in batch reactor experiments.

In the research presented in this paper, the phenomenon in batch reactors was observed and investigated. Considering that the dissolved heavy metal concentration and the suspended sediment concentration are uniformly distributed in batch reactors, equations describing (equilibrium) adsorption content of heavy metal pollutant on unit weight of sediment (or equilibrium particulate heavy metal concentration) and (equilibrium) dissolved heavy metal concentration were formulated and experimentally studied.

\section{Theoretical Considerations}

Adsorption models between the surface of solid particles and liquid (mainly water) originate from the adsorption theory between the solid surface and air (Stumn and Morgan 1981; Masel 1996; Langmuir 1997). Adsorption of heavy metal pollutants onto sediment particles is generally described by the adsorption isotherm and the adsorptive reaction kinetic equation. 


\section{Adsorption Isotherms}

Most experimental results indicate that the Henry adsorption isotherm is a proper expression for extremely low dissolved heavy metal concentration (Stumn and Morgan 1981).

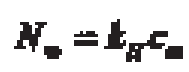

in which $\mathrm{N}_{\infty}$ is the equilibrium adsorption content of heavy metal pollutant on unit weight of sediment (the equilibrium particulate heavy metal concentration), $\mathrm{c}_{\infty}$ is the equilibrium dissolved heavy metal concentration, and $\mathrm{k}_{\mathrm{H}}$ is the distribution constant or Henry constant.

For general dissolved heavy metal pollutant concentrations, either the Freundlich adsorption isotherm, equation 2, or the Langmuir adsorption isotherm, equation 3, is used (Stumn and Morgan 1981; Chen et al. 1990; Huang and Wan 1995; Masel 1996; Langmuir 1997).

$$
\begin{aligned}
& N_{-}=k_{d} \\
& \mu_{n}=b \frac{c_{4}}{t+c_{*}}
\end{aligned}
$$

The former is a pure empirical one, where $k_{d}$ and $n$ are coefficients. In the Langmuir adsorption isotherm, $\mathrm{b}$ and $\mathrm{k}$ are the saturation adsorption content of heavy metal pollutant on unit weight of sediment and constant of adsorption-desorption rate, respectively.

\section{Adsorptive Reaction Kinetics Equations}

For extremely low dissolved heavy metal concentration (in the order of ppt), an adsorptive reaction kinetic equation of "Henry type" can be adopted (O'Connor 1988; Huang 1993).

$$
\frac{d N}{H}=k_{B 1} e-k_{g 2} N
$$

in which $\mathrm{N}$ is the particulate heavy metal concentration, $\mathrm{t}$ is time, $\mathrm{c}$ is dissolved heavy metal concentration, $k_{H 1}$ is the coefficient of adsorption rate, and $k_{H 2}$ is the coefficient of desorption rate. When an equilibrium adsorption is achieved (the left side of equation 4 approaches zero), equation 4 turns out to be the original Henry adsorption isotherm, which is valid for very low dissolved heavy metal concentration (Chen et al. 1990; Masel 1996; Langmuir 1997). Equation 4 indicates that variations of particulate heavy metal concentrations with time are positively proportional 
to the dissolved heavy metal concentration, $\mathrm{c}$, and negatively proportional to the absorbed amount, $\mathrm{N}$.

For general situations, an adsorptive reaction kinetic equation of “Langmuir type" can be adopted (O'Connor 1988; Huang 1993).

$$
\frac{A}{d}=k_{1} c(b-M-k
$$

in which $\mathrm{k}_{1}$ and $\mathrm{k}_{2}$ are the coefficients of adsorption rate and desorption rate, respectively, and $b$ is the saturation adsorption content of unit weight of sediment. Equation 5 implies that variations of the particulate heavy metal concentration with time is positively proportional to the product of the dissolved heavy metal concentration, c, and remained adsorption content, $\mathrm{b}-\mathrm{N}$, and negatively proportional to the absorbed amount, N. It should be pointed out that when an equilibrium adsorption is achieved (the left side of equation 5 equals to zero), equation 5 turns out to be the original Langmuir adsorption isotherm, which is valid in general situations (Stumn and Morgan 1981; Chen et al. 1990; Masel 1996; Langmuir 1997). Actually, the right-hand side of equation 5 is the rate of adsorption and the rate of desorption, respectively, used in the deduction of the Langmuir adsorption isotherm.

\section{Observations in Batch Reactor Experiments and Mathematical Description}

Batch reactor experiments on adsorption-desorption of heavy metal pollutants onto/off sediment in the laboratory are usually carried out in a small vessel of $100 \mathrm{~mL}$ with strong stirring. Under the condition of strong stirring, the suspended sediment concentration and the dissolved heavy metal concentration are uniformly distributed in the vessel. Experiments are usually conducted until equilibrium is reached. Considering the above-mentioned conditions, one can write the following equations:

1. Adsorptive reaction kinetic equation. These are equations 4 and 5, which are valid for very low dissolved heavy metal concentrations and general dissolved heavy metal concentrations, respectively.

2. Mass conservation equation. Total amount of heavy metal ions in a reactor, consisting of the dissolved phase and the particulate phase, remains constant at any time.

$$
M V+c\left(1-s / r, y=N_{0} s V+c_{\mathrm{b}}(1-s / r, y\right.
$$

in which $\mathrm{V}$ is the volume of water-sediment-pollutant mixture, $\mathrm{r}_{\mathrm{s}}$ is the specific weight of sediment particles, $\mathrm{s}$ is the suspended sediment concentration, $\mathrm{N}_{0}$ is the initial particulate heavy metal concentration, 
and $\mathrm{c}_{0}$ is the dissolved heavy metal concentration. Generally speaking, sediment concentration, $\mathrm{s}$, is low and $1-\mathrm{s} / \mathrm{r}_{\mathrm{s}} \cong 1$, therefore, equation 6a can be simplified as:

$$
M V+d V=N_{0} I V+c_{p} Y=A V
$$

in which $A=s N_{0}+c_{0}$.

3. Initial conditions of preceding set of equations are as follows, when $\mathrm{t}=0$,

$$
\begin{aligned}
& M_{m-\infty}=N_{0} \\
& c_{t \rightarrow 0}=c
\end{aligned}
$$

\section{Extremely Low Dissolved Heavy Metal Concentrations}

Under such conditions, equations 4 and 6 can be integrated with initial conditions of equation 7 .

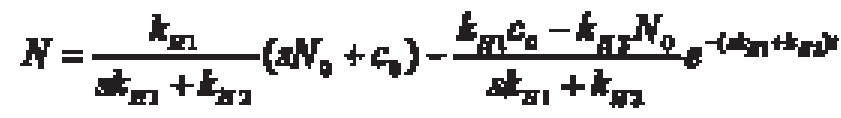

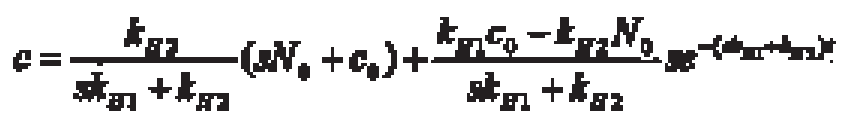

Equations 8 and 9 describe variations of the particulate heavy metal concentration, $\mathrm{N}$, and the dissolved heavy metal concentration, $\mathrm{c}$, with time, $t$. This paper discusses adsorption of heavy metal pollutants onto sediment particles. Therefore, one can always assume that the initial particulate heavy metal concentration, $\mathrm{N}_{0}$, equals zero. Equations 8 and 9 thus can be simplified as follows:

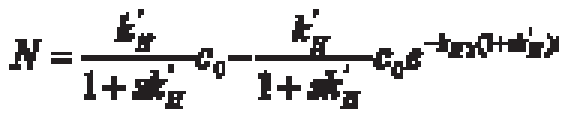

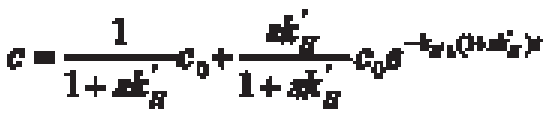

where $k_{\mathrm{r}}^{r}=\boldsymbol{k}_{\mathrm{r}} \boldsymbol{k}_{\mathrm{ax}}$

It can be deduced from equations 10 and 11 that $\mathrm{N}$ reaches its maximum value, $\boldsymbol{f}_{\mathbf{s}}(\mathbf{i})$ and $\mathrm{sN}$ reaches its minimum value when $\mathrm{s}$ approaches zero. This means that when the sediment concentration is very 
low, the particulate heavy metal concentration is high. However, the total adsorption amount by all the sediment is low due to the little amount of sediment and thus the dissolved heavy metal concentration, c, approaches its initial value, $\mathrm{c}_{0}$. Contrary, $\mathrm{N}$ reaches minimum and $\mathrm{sN}$ reaches maximum when s approaches infinity. This implies that when the sediment concentration is significantly high, almost all the heavy metal pollutant is adsorbed onto sediment and the dissolved heavy metal concentration is close to zero, but the particulate heavy metal concentration is very low.

When $t$ approaches infinity, that is, an equilibrium is reached, equations 10 and 11 turn to be :

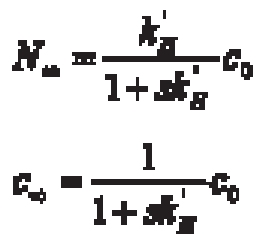

Under the equilibrium condition both the equilibrium particulate heavy metal concentration, $\mathrm{N}_{\infty}$, and the equilibrium dissolved heavy metal concentration, $\mathrm{c}_{\infty}$, are functions of the sediment concentration, $\mathrm{s}$, the initial dissolved heavy metal concentration, $\mathrm{c}_{0}$, and $k_{\mathrm{H}}^{\prime}$, which is the adsorptiondesorption characteristics of the sediment when interacting with heavy metal pollutants. Equations 12 and 13 can also be obtained directly by solving equations 1, 6 and 7. From equations 12 and 13 one can get:

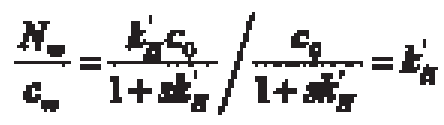

or

$$
N_{4}-k_{T}^{C_{*}}-k_{\Gamma} c_{4}
$$

This is just the Henry adsorption isotherm. It indicates that $\mathrm{N}_{\infty} / \mathrm{c}_{\infty}$ has nothing to do with the sediment concentration, but only depends on $k_{\mathrm{H}}^{\prime}\left(=\mathrm{k}_{\mathrm{H}}\right)$, the ratio between adsorption rate and the desorption rate or Henry constant, which is the property of the sediment interacting with heavy metal pollutants in the water.

It should be emphasized that the above discussion is only applicable to the situation of extremely low dissolved heavy metal concentration.

\section{General Dissolved Heavy Metal Pollutant Concentration}

For general situations, equations 5 and 6 can be solved in conjunction with the initial conditions of equation 7.

$$
\left|\frac{2 p W+q+\sqrt{q^{2}-4 p R}}{\left|2 p W+q-\sqrt{q^{2}-4 p R}\right|}\right|=\left|\frac{2 p W_{0}+q+\sqrt{q^{3}-4 p R}}{\left|2 p W_{0}+q-\sqrt{q^{2}-4 p R}\right|}\right|-\sqrt{r^{2}-4 \mu}
$$




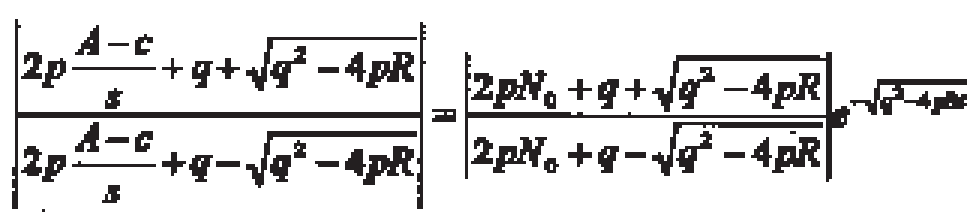

in which $\mathrm{p}=\mathrm{sk}_{1}, \mathrm{q}=-\left(\mathrm{A}+\mathrm{sbk}_{1}+\mathrm{k}_{2}\right), \mathrm{R}=\mathrm{Abk}_{1}$, and $\mathrm{A}=\mathrm{sN}_{0}+\mathrm{c}_{0}$.

Under the condition of $\mathrm{N}_{0}=0, \mathrm{c}_{0} \neq 0$ and $\mathrm{A}=\mathrm{sN}_{0}+\mathrm{c}_{0}=\mathrm{c}_{0}$, that is, sediment is not polluted at the very start, one may write down the following equations 16 and 17. Procedures of solving the set of equations can be found in Huang (1993).

$$
\begin{aligned}
& N=\frac{A_{1}-A_{2}-\left(A_{1}-A_{1}\right) t^{-4}}{2-2 \frac{A_{1}-A_{2}}{A_{1}+A_{1}} \theta^{-4}} \\
& c=c_{0}-t \frac{A_{1}-A_{1}-\left(A_{1}-A_{1}\right)-A_{1}}{2-2 \frac{A_{1}-A_{2}}{A_{1}+A_{2}}}
\end{aligned}
$$

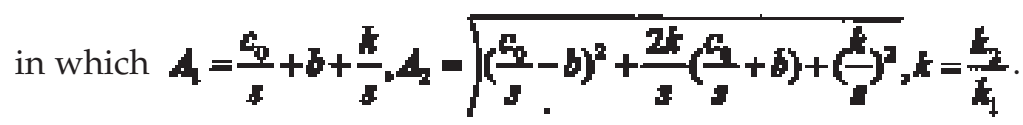

Equations 16 and 17 can be used to describe the kinetic adsorption process of heavy metal pollutants onto sediment in batch reactor experiments. When time, $t$, approaches infinity, an equilibrium is reached and one can get equations 18 and 19 from equations 16 and 17.

$$
\begin{aligned}
& N_{0}=\frac{1}{2}\left(\frac{c_{0}}{a}+b+\frac{t}{b} \sqrt{\left(\frac{c_{0}}{s}-b\right)^{2}+\frac{2}{a}\left(\frac{c_{0}}{g}+b\right)+\left(\frac{c^{2}}{g}\right)}\right) \\
& a_{-}=\frac{1}{2}\left(c_{0}-d-k+\sqrt{\left(c_{0}-s b\right)^{3}+2 k\left(c_{0}+b\right)+t^{2}}\right)
\end{aligned}
$$

From equations 18 and 19 , it can be seen that $\mathrm{N}_{\infty}$ and $\mathrm{c}_{\infty}$ are dependent on adsorption-desorption characteristics of sediment, $b$ and $k$, the initial dissolved heavy metal concentration, $\mathrm{c}_{0}$, and the suspended sediment concentration, s. Equations 18 and 19 can also be obtained directly by solving equations 3, 6 and 7 . With the Freundlich adsorption iostherm, one can also obtain the corresponding equations by solving equations 2, 6 and 7. From equations 18 and 19, one can get: 


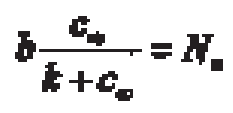

It is just the Langmuir adsorption isotherm, which is independent of the sediment concentration, although both the equilibrium particulate heavy metal concentration and the equilibrium dissolved heavy metal concentration are related to the sediment concentration. That is to say, if a proper adsorption model, such as the Langmuir adsorption model is applied, the factor of the sediment concentration should be eliminated from the relationship between $\mathrm{N}_{\infty}$ and $c_{\infty}$.

A great deal of attention is usually paid to the equilibrium particulate heavy metal concentration, $\mathrm{N}_{\infty}$, in experimental research (Jin and Wang 1988; YRWRPRI 1988; Herbert et al. 1995; Herut et al. 1995; Bird and Evenden 1996). From equation 18 it can be seen that $\mathrm{N}_{\infty}$ is dependent on three factors and they are $c_{0} / \mathrm{s}, \mathrm{b}$ and $\mathrm{k} / \mathrm{s}$. The $\mathrm{c}_{0} / \mathrm{s}$, the ratio of the initial dissolved heavy metal concentration and the sediment concentration and noted as "the ratio of solid and liquid" (Jin and Wang 1988), is the external condition. The saturation adsorption content of heavy metal on unit weight of sediment, $b$, is the inherent property of sediment (also related to heavy metal itself). Because $\mathrm{k}$, the ratio of coefficient of desorption rate and coefficient of adsorption rate, is also the inherent property of sediment, the $\mathrm{k} / \mathrm{s}$ denotes the effect of inside condition and outside condition on $\mathrm{N}_{\infty}$. By equation 18, some experimental phenomena could be well explained. For example, while diluting the reaction system (both $\mathrm{c}_{0}$ and $\mathrm{s}$ decrease simultaneously) and keeping $\mathrm{c}_{0} / \mathrm{s}$ constant, it is always found that $\mathrm{N}_{\infty}$ varies in the experiment (Jin and Wang 1988). It is evident that $\mathrm{k} / \mathrm{s}$ varies while diluting the experimental system and $\mathrm{N}_{\infty}$ varies consequently.

\section{Experiments}

\section{Pre-treatment of Sediment Samples}

Sediment samples were taken from the Yellow River, China. Deposits in the setting basin of the Zhengzhou Water Company were collected and freeze-dried under low temperature $\left(-20\right.$ to $\left.-25^{\circ} \mathrm{C}\right)$. The dried sediments were then sieved manually through nylon sieves of 460 mesh to get experimental sediment samples finer than $0.033 \mathrm{~mm}$. Reagents used in analysis were all chemical grade. All glass and plastic ware used for experiments were previously soaked in $10 \%(\mathrm{v} / \mathrm{v})$ nitric acid overnight and rinsed five times with double-deionized water prior to use.

\section{Equilibrium Adsorption Experiments}

In equilibrium adsorption experiments, a defined amount of sediment samples were put into beakers of $100 \mathrm{~mL}$, in which there was double-deionized water of defined volume. Held stationary at a constant temperature, they were kept for a night. Next, a solution of cadmium ions 
with defined concentration was added into the beakers. The beakers were vibrated in a constant-temperature case for two hours, and were kept stationary overnight. Afterwards, about $10-\mathrm{mL}$ aliquots were filtered through a $0.5-\mu \mathrm{m}$ membrane filter and the cadmium ion concentration in the filtrate was measured with an atomic (flame) adsorption spectrophotometer. By comparing the measured cadmium ion concentration with the cadmium ion concentration in the blank solution, the adsorption content of cadmium ions onto unit weight of sediment (the particulate cadmium concentration) was established. It was assumed that the difference between the cadmium added and that remaining in solution was adsorbed onto the sediment (Warren and Zimmerman 1994).

One set of equilibrium adsorption experiments was conducted to study the effect of suspended sediment concentration on the parameters in adsorption isotherms. Experimental conditions are shown in Table 1.

Two sets of equilibrium adsorption experiments were carried out to investigate variations of the equilibrium particulate cadmium concentrations, $\mathrm{N}_{\infty}$, with sediment concentrations, s. Experimental conditions are shown in Table 2.

\section{Dynamic Adsorption Experiments}

Dynamic adsorption experiments were carried out in beakers of $500 \mathrm{~mL}$ with continuous stirring. Double-deionized water of defined volume, sediment particles of defined concentrations and cadmium ion solution of defined concentrations in the beakers were stirred continuously under a constant temperature. Cadmium ion concentration in the filtrate was measured and recorded at defined time intervals. During the sampling process, the sediments in the beakers were kept suspended by agitating the beakers. Overall processes of the experiments were operated in parallel.

One set of dynamic adsorption experiments was conducted to study effects of initial dissolved cadmium concentrations and sediment concentrations on adsorption processes of cadmium ion, respectively. Experimental conditions are shown in Table 3.

Table 1. Experimental conditions for studying the effect of sediment concentration on the parameters on adsorption isotherms

\begin{tabular}{|c|c|c|c|}
\hline No. & $\begin{array}{l}\text { Suspended sediment } \\
\text { concentrations } \\
\mathrm{s}\left(\mathrm{kg} / \mathrm{m}^{3}\right)\end{array}$ & $\begin{array}{l}\text { Initial dissolved cadmium } \\
\text { concentrations } \\
\mathrm{c}_{0}(\mathrm{mg} / \mathrm{L})\end{array}$ & Remarks \\
\hline 1.1 & $\mathrm{~s}=5,10,15,20$ & $c_{0}=2,3,4,5,6,7$ & $27-28^{\circ} \mathrm{C}, \mathrm{pH}: 6-7$ \\
\hline 1.2 & $s=20,25,30,35,40$ & $c_{0}=3,5,7,9,11,13$ & \\
\hline 1.3 & $\mathrm{~s}=40,45,50,55$ & $\mathrm{c}_{0}=6,8,10,12,14,16$ & \\
\hline
\end{tabular}


Table 2. Experimental conditions for investigating the effect of $s$ on $\mathrm{N}_{\infty}$

\begin{tabular}{cccc}
\hline \hline No. & $\mathrm{s}\left(\mathrm{kg} / \mathrm{m}^{3}\right)$ & $\mathrm{c} 0(\mathrm{mg} / \mathrm{L})$ & Remarks \\
\hline 1 & $1.0,5.0,10.0,25.0,50.0,100.0$ & 3.0 & $15 \sim 16^{\circ} \mathrm{C}, \mathrm{pH}: 6 \sim 7$ \\
2 & $1.0,5.0,10.0,25.0,50.0,100.0$ & 4.0 & $16 \sim 17^{\circ} \mathrm{C}, \mathrm{pH}: 6 \sim 7$ \\
\hline
\end{tabular}

\section{Results and Discussion}

\section{Effect of Sediment Concentration on the Parameters in Adsorption Isotherms}

Both the Langmuir adsorption isotherm and the Freundlich adsorption isotherm were applied to fit the data in Table 1. Parameters $b$ and $k$ in the Langmuir adsorption isotherm, and $\mathrm{k}_{\mathrm{d}}$ and $\mathrm{n}$ in the Freundlich adsorption isotherm computed by the least squares method and corresponding errors are listed in Tables $4 \mathrm{~A}$ and $4 \mathrm{~B}$, respectively. In Table 4 , the errors $\%$ means the absolute value of $\left(\mathrm{N}_{\infty}\right.$ measured $-\mathrm{N}_{\infty}$ calculated $) / \mathrm{N}_{\infty}$ measured.

In Table 4 parameters $b, k, k_{d}$, and $n$ were calculated in two different ways. Firstly, they were computed separately for each run of experiments, that is, each sediment concentration had a set of parameters. Secondly, they were computed for the set, including 13 runs. Accordingly, in Table 4 errors are given in two different ways.

According to the comparison of errors, the Langmuir adsorption isotherm fits the experimental data better than the Freundlich adsorption isotherm for the Yellow River sediment (YRWRPRI 1988; Huang 1993).

Table 3. Experimental conditions for studying the effect of $\mathrm{c}_{0}$ and $\mathrm{s}$ on $\mathrm{c}(\text { or on } \mathrm{N})^{\mathrm{a}}$

\begin{tabular}{|c|c|c|c|c|c|c|c|c|}
\hline \multirow{2}{*}{$\begin{array}{l}\text { No. } \\
\text { effect of } c_{0}\end{array}$} & \multirow[b]{2}{*}{$\mathrm{c}_{0}$} & \multicolumn{6}{|c|}{ Experimental results } & \multirow{2}{*}{$\begin{array}{c}\text { Remarks } \\
\mathrm{s}=1 \mathrm{~kg} / \mathrm{m}^{3}, \\
26 \sim 27^{\circ} \mathrm{C}, \\
\mathrm{pH}: 6 \sim 7\end{array}$} \\
\hline & & 0.5 & 1.0 & 1.5 & 2.0 & 2.5 & 3.0 & \\
\hline & $\mathrm{k}_{1}$ & 0.02445 & 0.00345 & 0.00070 & 0.00018 & 0.00036 & 0.00009 & \\
\hline \multirow[t]{2}{*}{ effect of $s$} & $\mathrm{~s}$ & 1 & 5 & 10 & 25 & & & $\begin{array}{c}\mathrm{c}_{0}=2 \mathrm{mg} / \mathrm{L} \\
21 \sim 22^{\circ} \mathrm{C} \\
\mathrm{pH}: 6 \sim 7\end{array}$ \\
\hline & $\mathrm{k}_{1}$ & 0.0180 & 0.0241 & 0.0259 & 0.0213 & & & \\
\hline
\end{tabular}

${ }^{a} \mathrm{k}_{1}$ is in $\mathrm{L} /(\mathrm{mg} . \mathrm{s}), \mathrm{c}_{0}$ is in $\mathrm{mg} / \mathrm{L}$ and $\mathrm{s}$ is in $\mathrm{kg} / \mathrm{m}^{3}$. 
Table 4A. Parameters $\mathrm{b}$ and $\mathrm{k}$ in the Langmuir adsorption isotherm and errors

\begin{tabular}{|c|c|c|c|c|}
\hline \multirow[b]{2}{*}{$\mathrm{s}\left(\mathrm{kg} / \mathrm{m}^{3}\right)$} & \multicolumn{3}{|c|}{$\begin{array}{l}\text { Langmuir adsorption isotherm } \\
\text { For each run }\end{array}$} & \multirow{2}{*}{$\begin{array}{l}\text { For the set } \\
\text { Errors (\%) }\end{array}$} \\
\hline & $\mathrm{b}(\mathrm{mg} / \mathrm{g})$ & $\mathrm{k}(\mathrm{mg} / \mathrm{L})$ & Errors (\%) & \\
\hline 5 & 0.351 & 0.255 & $-3.9 \sim 1.8$ & $-22.6 \sim-4.2$ \\
\hline 10 & 0.369 & 0.145 & $0.0 \sim 0.0$ & $-21.1 \sim 11.6$ \\
\hline 15 & 0.334 & 0.092 & $0.0 \sim 0.0$ & $-4.9 \sim 1.7$ \\
\hline 20 & 0.318 & 0.088 & $0.0 \sim 0.0$ & $-14.2 \sim 7.1$ \\
\hline 20 & 0.398 & 0.179 & $0.0 \sim 0.0$ & $-21.5 \sim 16.3$ \\
\hline 25 & 0.344 & 0.097 & $-8.4 \sim 14.3$ & $-9.4 \sim 11.0$ \\
\hline 30 & 0.362 & 0.096 & $-9.4 \sim 9.9$ & $-5.2 \sim 11.9$ \\
\hline 35 & 0.368 & 0.101 & $0.0 \sim 0.0$ & $-10.5 \sim 23.2$ \\
\hline 40 & 0.296 & 0.055 & $0.0 \sim 0.0$ & $-5.8 \sim 25.2$ \\
\hline 40 & 0.360 & 0.102 & $0.0 \sim 0.0$ & $-2.6 \sim 5.4$ \\
\hline 45 & 0.320 & 0.076 & $0.0 \sim 0.0$ & $-7.4 \sim 7.1$ \\
\hline 50 & 0.310 & 0.068 & $0.0 \sim 0.0$ & $-4.7 \sim 8.6$ \\
\hline 55 & 0.301 & 0.060 & $0.0 \sim 0.0$ & $-2.7 \sim 19.5$ \\
\hline For the set & 0.342 & 0.091 & & \\
\hline
\end{tabular}

Table 4B. Parameters $\mathrm{kd}$ and $\mathrm{n}$ in the Freundlich adsorption isotherm and errors

\begin{tabular}{|c|c|c|c|c|}
\hline \multirow[b]{2}{*}{$\mathrm{s}\left(\mathrm{kg} / \mathrm{m}^{3}\right)$} & \multicolumn{3}{|c|}{$\begin{array}{l}\text { Langmuir adsorption isotherm } \\
\text { For each run }\end{array}$} & \multirow{2}{*}{$\begin{array}{l}\text { For the set } \\
\text { Errors (\%) }\end{array}$} \\
\hline & $\mathrm{k}_{\mathrm{d}}$ & $\mathrm{n}$ & Errors (\%) & \\
\hline 5 & 0.271 & 4.937 & $-0.7 \sim 0.3$ & $-24.8 \sim-11.0$ \\
\hline 10 & 0.308 & 4.393 & $-7.1 \sim 12.2$ & $-20.4 \sim 6.1$ \\
\hline 15 & 0.326 & 3.628 & $-15.3 \sim 10.9$ & $-21.1 \sim 9.6$ \\
\hline 20 & 0.392 & 2.485 & $-15.0 \sim 12.6$ & $-18.0 \sim 12.7$ \\
\hline 20 & 0.308 & 3.673 & $-4.4 \sim 6.1$ & $-9.4 \sim 3.4$ \\
\hline 25 & 0.305 & 3.783 & $-11.4 \sim 9.1$ & $-14.7 \sim 8.8$ \\
\hline 30 & 0.370 & 2.890 & $-14.5 \sim 11.2$ & $-23.3 \sim 16.9$ \\
\hline 35 & 0.464 & 2.279 & $-8.6 \sim 8.1$ & $-31.9 \sim 21.6$ \\
\hline 40 & 0.458 & 2.351 & $-17.1 \sim 8.8$ & $-42.6 \sim 14.4$ \\
\hline 40 & 0.386 & 2.897 & $-7.3 \sim 4.5$ & $-5.8 \sim 14.2$ \\
\hline 45 & 0.350 & 3.227 & $-11.6 \sim 13.1$ & $-10.3 \sim 16.2$ \\
\hline 50 & 0.380 & 2.905 & $-10.1 \sim 8.9$ & $-12.6 \sim 12.0$ \\
\hline 55 & 0.433 & 2.650 & $-5.5 \sim 6.5$ & $-12.7 \sim 13.1$ \\
\hline For the set & 0.319 & 3.535 & & \\
\hline
\end{tabular}


This implies that there is a saturation adsorption content, $b$, for the Yellow River sediment.

As for the effect of sediment concentrations on parameters $b$ and $k$ in the Langmuir adsorption isotherm, as shown in Fig. $1 \mathrm{~A}$ and $1 \mathrm{~B}$ and Table 4 , it seems that $\mathrm{b}$ and $\mathrm{k}$ neither systematically vary with sediment concentrations nor with initial dissolved cadmium concentrations (Huang and Wan 1995). The variations of $b$ and $k$ with s seems to be caused by experimental technologies and can partly be attributed to "the incompleteness of filtration" (McKinley and Jenne 1991). Thus, one may obtain the following significant conclusion: if a proper model, for instance, the Langmuir adsorption isotherm is adopted, characteristic parameters, $\mathrm{b}$ and $\mathrm{k}$ in the adsorption isotherm are independent of the sediment concentration, s, and the initial dissolved heavy metal (cadmium ions here) concentration, $\mathrm{c}_{0}$.

In reality, the sediment concentration does not affect the property of sediment and has little effect on property of the solution. Although the sediment concentration has a significant effect on the equilibrium particulate heavy metal concentration, $\mathrm{N}_{\infty}$, and the equilibrium dissolved heavy metal concentration, $\mathrm{C}_{\infty}$, as shown in equations 18 and 19 (as shown in the following paragraph), if $\mathrm{N}_{\infty}$ and $\mathrm{c}_{\infty}$ are linked by a proper adsorption isotherm, for instance, the Lagmuir adsorption isotherm, the factor of sediment concentration disappears in the equation.

\section{Variations of Equilibrium Particulate Cadmium Concentrations with Sediment Concentrations}

Figure 2 shows the equilibrium particulate cadmium concentration, $\mathrm{N}_{\infty}$, as a function of sediment concentrations. The data is from Table 2.

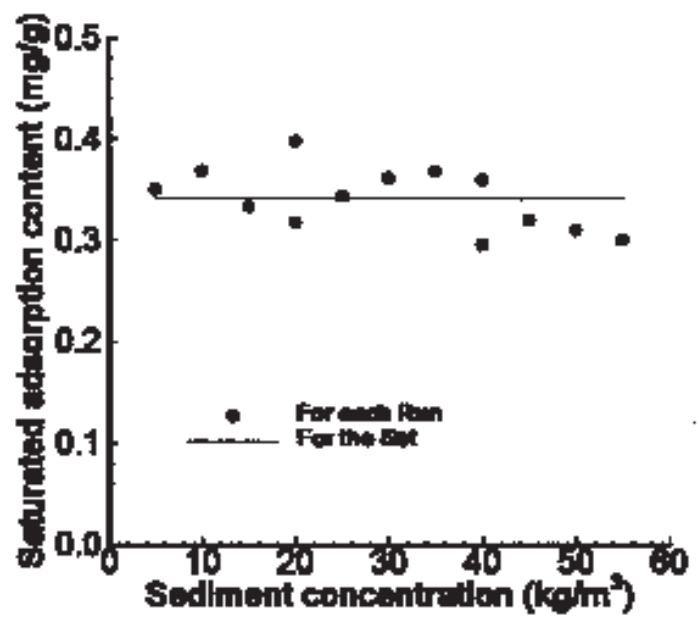

Fig. 1A. Relationship between the saturated adsorption content and the sediment concentration. 


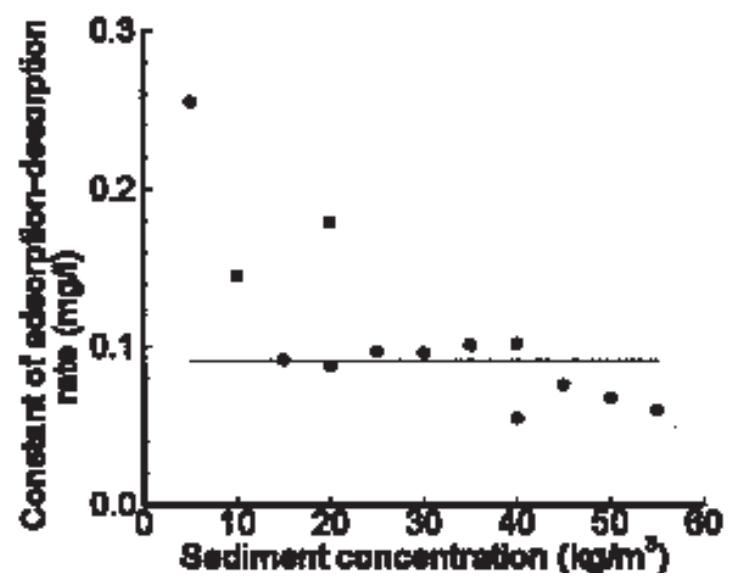

Fig. 1B. Relationship between the constant of adsorption-desorption rate and the sediment concentration.

Curves in Fig. 2 are calculated by equation 18. Because both $\mathrm{b}$ and $\mathrm{k}$ are independent of sediment concentrations, parameters $b$ and $k$ in equation 18 were determined by the least squares method to fit the experimental data. They are $b=0.319 \mathrm{mg} / \mathrm{g}$ and $\mathrm{k}=0.133 \mathrm{mg} / \mathrm{L}$ for run 1 and $\mathrm{b}=0.337 \mathrm{mg} / \mathrm{g}$ and $\mathrm{k}=0.232 \mathrm{mg} / \mathrm{L}$ for run 2 . It can be seen from Fig. 2 that the equilibrium particulate cadmium concentration decreases with increasing sediment concentration. Moreover, it can be noted that when the sediment concentration is small, increment or decrement of the sed-

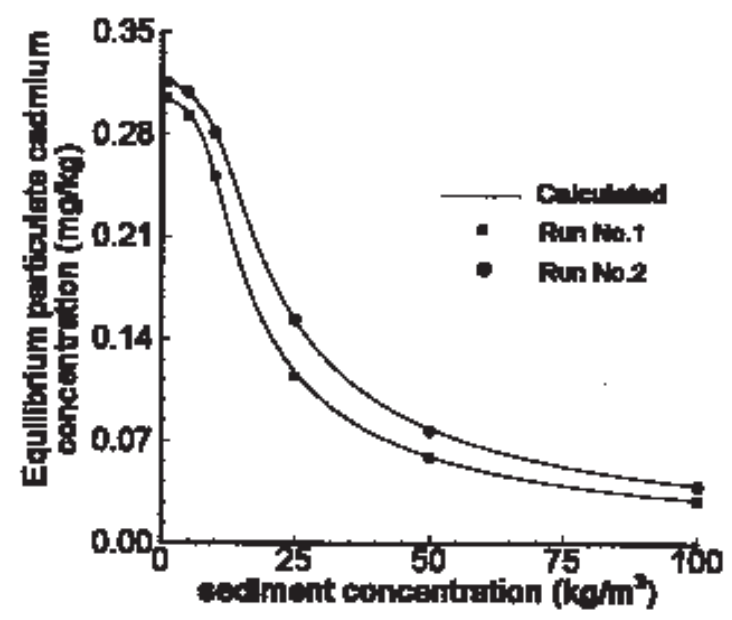

Fig. 2. Variation of equilibrium particulate cadmium concentration with sediment concentration. 
iment concentration has a bigger effect on $\mathrm{N}_{\infty}$. From equation 18 one may get the following.

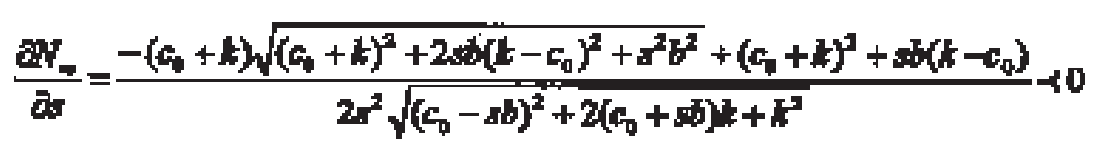

Effect of Initial Dissolved Heavy Metal Concentrations on Equilibrium Particulate Heavy Metal Concentrations

From equation 18 one can derive :

$$
\frac{B F_{0}}{c_{0}}=\frac{1}{2 s}\left(1-\frac{c_{0}-s+k}{\sqrt{\left(c_{0}-s b\right)^{2}+2 k\left(c_{0}+s b\right)+k^{2}}}\right)+0
$$

That is to say, the equilibrium particulate heavy metal concentration increases with increasing initial dissolved heavy metal concentrations.

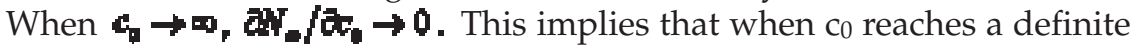
value, $\mathrm{N}_{\infty}$ increases little with increasing $\mathrm{c}_{0}$, as shown in Fig. 3 (the data is from Table 1). This is because there is a saturation adsorption content for the sediment.

\section{Variations of the Adsorption Capacity with Sediment Concentrations}

The equilibrium particulate heavy metal concentration decreases with increasing sediment concentrations. However, experience deduced

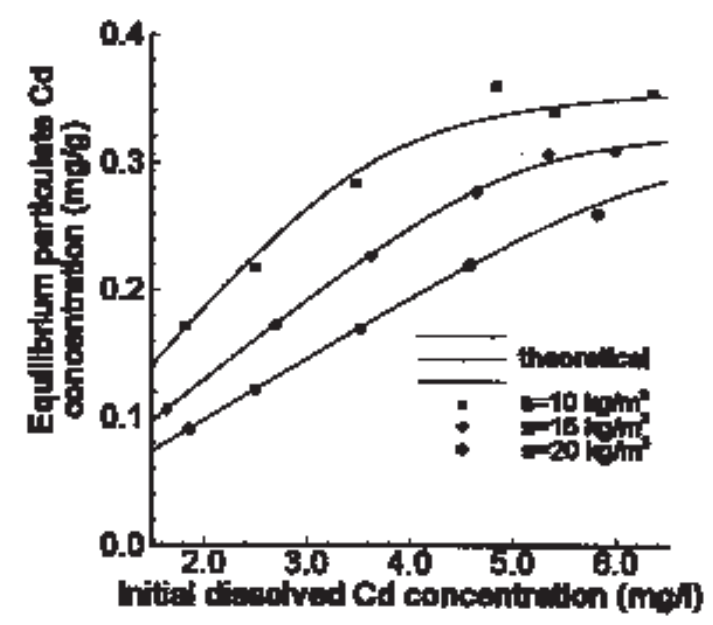

Fig. 3. Equilibrium particulate cadmium concentration as a function of initial cadmium concentrations. 
from practice (YRWRPRI 1988) is that the higher the sediment concentration, the larger the amount of heavy metal pollutant conveyed by a river. The adsorption capacity is defined as the amount of heavy metal pollutant adsorbed by sediment in unit volume of (muddy) water. It can be written as:

$$
Q=\Delta N_{-}
$$

in which $\mathrm{Q}$ is the adsorption capacity in $\mathrm{g} / \mathrm{m}^{3}$. In the experiment, $\mathrm{N}_{\infty}$ is described by equation 18, therefore:

$$
Q-N_{0}=\frac{1}{2}\left(c_{0}+\infty+k-\sqrt{\left(c_{1}-\infty\right)^{2}+2\left(c_{0}+s b\right)+k^{2}}\right)
$$

Differentiating with respect to s, one may write:

$$
\frac{\partial Q}{\partial t}=\frac{1}{2}\left(b-b \frac{a-\phi+k}{\sqrt{\left(c_{0}-\phi\right)^{2}+2 z\left(c_{0}+\omega\right)+k^{2}}}\right)>0
$$

That is to say, the adsorption capacity increases with increasing the sediment concentration. And when $\mathbf{s} \rightarrow \mathbf{\infty}, \mathbf{0} / \mathbf{\alpha} \rightarrow \mathbf{0}$. This implies that when the sediment concentration increases over a certain value, the adsorption capacity does not increase remarkably, as shown in Fig. 4 (the data is from Table 2).

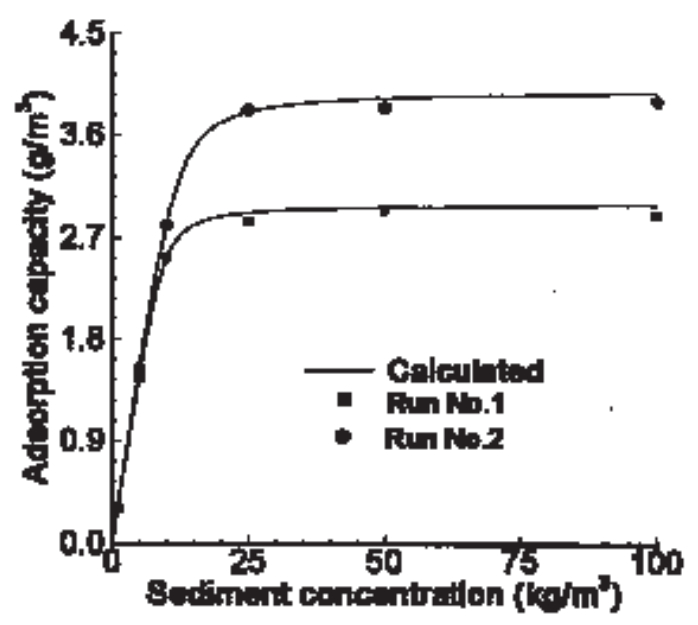

Fig. 4. Variation of adsorption capacity with sediment concentration. 
Differentiating equation 22 with respect to $c_{0}$, one obtains:

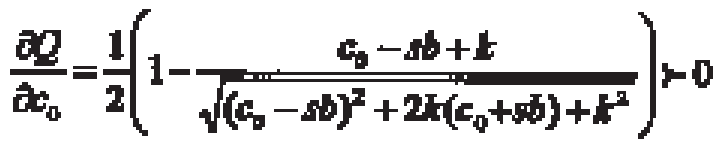

It can be seen that if $\mathrm{s}$ and other conditions remain constant, the adsorption capacity increases with increasing the initial dissolved heavy metal concentration, $\rightarrow \infty$, and $\boldsymbol{\phi} \mathbf{D} / \boldsymbol{a}_{\mathbf{0}} \rightarrow \mathbf{0}$. This implies that there is a limitation for variations of $\mathrm{Q}$ with $\mathrm{c}_{0}$, too. This is also because there exists a saturation adsorption content for the sediment.

Because adsorption capacity of a river may be considered as its selfpurification capacity of heavy metal pollutants to some extent, the study of the relationship among adsorption capacity, sediment concentration and initial dissolved heavy metal concentration, has significance for exploiting water resources and making rational use of aquatic environmental capacities.

\section{Effect of the Initial Dissolved Heavy Metal Concentration and the Sediment Concentration on Adsorption Processes}

From equation 18 or 19 one may note that there are four factors affecting the particulate heavy metal concentration and dissolved heavy metal concentrations. They are initial dissolved heavy metal concentrations, sediment concentrations, time and adsorption-desorption characteristics of sediment, which consist of the saturation adsorption content, $\mathrm{b}$, constant of adsorption-desorption rate, $\mathrm{k}\left(=\mathrm{k}_{2} / \mathrm{k}_{1}\right)$ and coefficient of adsorption rate, $\mathrm{k}_{1}$ (or coefficient of desorption rate $\mathrm{k}_{2}$ ). Two of them, $\mathrm{c}_{0}$ and $\mathrm{s}$, belong to external conditions.

Figure 5 shows the dissolved cadmium concentration as a function of time for different initial dissolved cadmium concentrations with the sediment concentration $1.0 \mathrm{~kg} / \mathrm{m}^{3}$. In the figure, curves were calculated by equation 19 by the least squares method to fit the experimental data (Table 3). Parameters, b and $\mathrm{k}$ calculated are $0.495 \mathrm{mg} / \mathrm{g}$ and $0.253 \mathrm{mg} / \mathrm{L}$, respectively. Generally, the larger the initial dissolved cadmium concentration, the larger the amount absorbed by sediment and the less the coefficient of adsorption rate. As shown in Table 3, under the condition of constant sediment concentration coefficients of adsorption rate, $\mathrm{k}_{1}$, decrease with increasing the initial dissolved cadmium concentration.

Figure 6 shows the dissolved cadmium concentration as a function of time for different sediment concentrations with the initial dissolved cadmium concentration of $2 \mathrm{mg} / \mathrm{L}$, where curves were calculated using equation 19 by the least squares method to fit the experimental data. Parameters $\mathrm{b}$ and $\mathrm{k}$ obtained in the calculation are $0.300 \mathrm{mg} / \mathrm{g}$ and $0.185 \mathrm{mg} / \mathrm{L}$, respectively. From equation 18 or 19 it is easily found that the sediment concentration is a factor affecting the particulate heavy metal concentration and the dissolved heavy metal concentration. But, accord- 


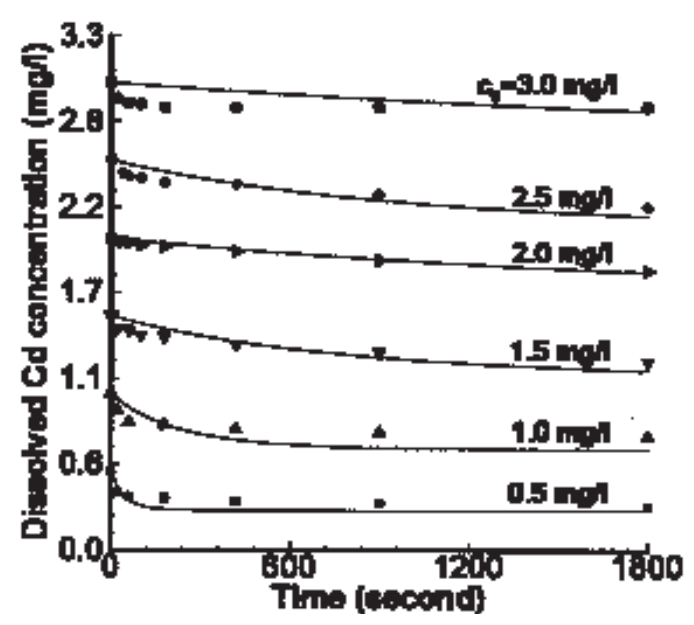

Fig. 5. Variation of dissolved cadmium concentration with time.

ing to the experimental data available in the research, as shown in Table 3 and Fig. 6, the sediment concentration has no effect on the coefficient of adsorption rate, $\mathrm{k}_{1}$ (or coefficient of desorption rate $\mathrm{k}_{2}$ ).

Experiments also indicate that equilibrium adsorption of cadmium ions by the Yellow River sediments can be achieved very quickly, generally in about thirty minutes or one hour, as found in the literature (YRWRPRI 1988).

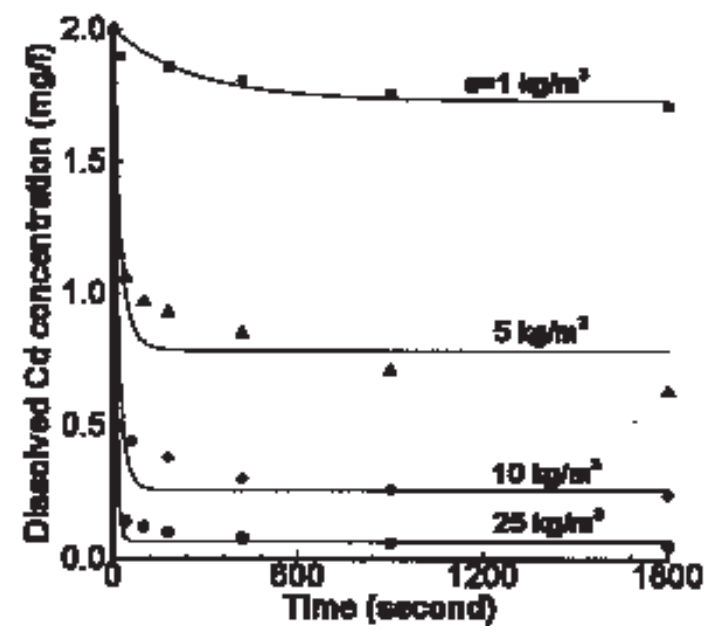

Fig. 6. Variation of dissolved cadmium concentration with time. 


\section{Conclusions}

1. The experiments indicate that the equilibrium adsorption of cadmium ions by the Yellow River sediment follow the Langmuir adsorption isotherm and there exists a saturation adsorption content for the Yellow River sediment.

2. The fact that the dissolved heavy metal concentration and the sediment concentration are uniformly distributed in batch reactors was observed. Taking advantage of it, variations in the dissolved heavy metal concentration and the particulate heavy metal concentration with time were formulated in the research by the use of the adsorptive reaction kinetic equation, and mass balance equation with its initial conditions. These are equations 10 and 11 for extremely low dissolved heavy metal concentrations, and equations 16 and 17 for general dissolved heavy metal concentrations. Moreover, equations for calculating the equilibrium particulate heavy metal concentration and the equilibrium dissolved heavy metal concentration were also obtained. These can be used as a tool for further study.

3. Theoretical analysis and experimental results demonstrate that there is an "effect of solids concentration," that is, under the same condition, the particulate heavy metal concentration decreases with increasing sediment concentration. This can be well explained by the law of mass conservation, as shown in equations 12 and 13 for extremely low dissolved heavy metal concentrations and equations 18 and 19 for general dissolved heavy metal concentrations. The adsorption isotherm itself is not influenced by the sediment concentration. This means that parameters in the adsorption isotherm do not change with the sediment concentration provided a proper adsorption isotherm is adopted.

4. Experimental data demonstrate that the relationship between the equilibrium particulate heavy metal concentration and the sediment concentration, as shown in Fig. 2, are convex curves. There is a saturation adsorption content for the sediment.

5. Adsorption capacity defined as the amount of heavy metal pollutant absorbed by unit volume of (muddy) water increases with increasing sediment concentrations and initial dissolved heavy metal concentrations. Its increasing rate of the adsorption capacity is larger at the beginning and then gradually decreases.

6. Under the same condition, the coefficient of adsorption rate, $\mathrm{k}_{1}$, in the adsorptive reaction kinetics equation of the Langmuir type, decreases with increasing initial dissolved heavy metal concentration. The sediment concentration has no effect on the coefficient of adsorption rate, $\mathrm{k}_{1}$. 


\section{Acknowledgements}

The National Natural Science Foundation of China funds the main work of the manuscript, the first submitted version of the manuscript was finished at the National Centre for Computational Hydro Science and Engineering, The University of Mississippi. I would like to give thanks to the National Natural Science Foundation of China for the financial support. I also would like to give sincere thanks to The Yellow River Water Resources Protection and Research Institute for helping collect sediment samples. My special thanks go to Zhao Hui Wan and Sam S.Y. Wang for long-time encouragement and guidance. I am grateful to two anonymous reviewers for their very good comments.

\section{References}

Bird GA, Evenden WG. 1996. Transfer of ${ }^{60} \mathrm{Co},{ }^{65} \mathrm{Zn},{ }^{95} \mathrm{Tc},{ }^{134} \mathrm{Cs}$ and ${ }^{238} \mathrm{U}$ from water to organic sediment. Water Air Soil Pollut. 11:251-261.

Chen JS, Deng BS, Tao S, Cheng CQ. 1990. Environmental geochemistry (in Chinese), Ocean Press of China.

Förstner U, Wittmann TGW. 1981. Metal pollution in the aquatic environment, $2^{\text {nd }}$ ed. Springer-Verlag, Berlin.

Hart BT. 1986. Water quality management-the role of particulate matter in the transport and fate of pollutants. Water Studies Center, Chisholm Institute of Technology, Melbourne.

Herbert EA, Chen YT, Li YM, Huang CP. 1995. Soil partition coefficients for Cd by column desorption and comparison to batch adsorption measurements. Environ. Sci. Technol. 29:1887-1891.

Herut B, Hornung H, Kress N, Krom MD, Shirav M. 1995. Trace metals in sediments at the lower reaches of Mediterranean coastal rivers, Israel. Water Sci. Technol. 32:239-246.

Horowitz AJ. 1995. The use of suspended sediment and associated trace elements in water quality studies. IAHS Special Publication No. 4, Printed in Great Britain by Galliard (Printers) Ltd., Great Yarmouth.

Horowitz AJ, Elrick KA. 1987. The relation of stream sediment surface area, grain size and composition to trace element chemistry. Appl. Geochem. 2:437-451.

Huang SL. 1993. The effect of sediment motion on transport-transformation of heavy metal pollutants (in Chinese). Ph.D. Dissertation, Chinese Institute of Water Conservancy and Hydroelectric Power Research, Beijing, China.

Huang SL, Wan ZH. 1995. Present state of experimental research on heavy metal pollutant adsorption-desorption by sediment. Int. J. Sed. Res. 10:69-81.

Jin XC, Wang GL. 1988. Study on the effect of sediment on 'the effect of sediment concentration on adsorption of heavy metal pollutant.' Environ. Sci. Inform. (in Chinese) 5:17-25.

Langmuir D. 1997. Aqueous environmental geochemistry. Prentice-Hall, Inc.

Lau SSS, Chu LM. 2000. The significance of sediment contamination in a coast wetland, Hong Kong, China. Water Res. 34:379-386. 
Masel RI. 1996. Principles of adsorption and reaction on solid surfaces. John Wiley and Sons, Inc.

McKinley PJ, Jenne EA. 1991. Experimental investigation and review of the "solids concentration" effect in adsorption studies. Environ. Sci. Technol. 25:2082-2087.

O'Connor JD. 1988. Models of sorptive toxic substances in freshwater systems. I: basic equations. J. Environ. Eng. 114:507-532.

Stumm W, Morgan JJ. 1981. Aquatic chemistry-an introduction emphasizing chemical equilibrium in natural waters, $2^{\text {nd }} \mathrm{ed}$. John Wiley and Sons, Inc.

Warren LA, Zimmerman AP. 1994. The influence of temperature and $\mathrm{NaCl}$ on cadmium, copper and zinc partitioning among suspended particulates and dissolved phases in an urban river. Water Res. 28:1921-1931.

YRWRPRI. 1988. Effect of sediment from the middle of the Yellow River on heavy metal pollutant transport-transformation (in Chinese). The Yellow River Water Resources Protection and Research Institute.

\section{Notations}

$\mathrm{N}_{\infty}=$ equilibrium adsorption content by unit weight of sediment (or equilibrium particulate heavy metal concentration), $\mathrm{mg} / \mathrm{g}$.

$\mathrm{c}_{\infty}=$ equilibrium dissolved heavy metal concentration, $\mathrm{mg} / \mathrm{L}$.

$\mathrm{b}=$ saturation adsorption content of heavy metal pollutant of unit weight of sediment, $\mathrm{mg} / \mathrm{g}$.

$k_{H 1}=$ coefficient of adsorption rate in the adsorptive reaction kinetics equation of Henry type, L/(g.s).

$k_{\mathrm{H} 2}=$ coefficient of desorption rate in the adsorptive reaction kinetics equation of Henry type, $1 / \mathrm{s}$.

$k_{H}^{\prime}=k_{H 1} / k_{H 2}, \mathrm{~L} / \mathrm{g}$.

$\mathrm{k}_{\mathrm{H}}=$ distribution constant or Henry constant, L/g.

$\mathrm{k}=$ ratio of coefficient of adsorption rate and coefficient of desorption rate (or constant of adsorption-desorption rate) $\left(\mathrm{k}=\mathrm{k}_{2} / \mathrm{k}_{1}\right), \mathrm{mg} / \mathrm{L}$.

$\mathrm{N}_{0}=$ initial content of heavy metal pollutant on unit weight sediment particles (or initial particulate heavy metal concentration), $\mathrm{mg} / \mathrm{g}$.

$\mathrm{s}=$ sediment concentration, $\mathrm{kg} / \mathrm{m}^{3}$.

$\mathrm{k}_{1}=$ coefficient of adsorption rate, $\mathrm{L} /$ (mg.s).

$\mathrm{k}_{2}=$ coefficient of desorption rate, $1 / \mathrm{s}$.

$\mathrm{N}=$ adsorption content of heavy metal pollutant of unit weight sediment (or particulate heavy metal concentration), $\mathrm{mg} / \mathrm{g}$.

$\mathrm{c}=$ dissolved heavy metal concentration, $\mathrm{mg} / \mathrm{L}$.

$\mathrm{t}=$ time, $1 / \mathrm{s}$.

$\mathrm{V}=$ volume of water-sediment-pollutant mixture, $\mathrm{mL}$.

$\mathrm{r}_{\mathrm{s}}=$ specific weight of sediment particles, $\mathrm{kg} / \mathrm{m}^{3}$.

$\mathrm{Q}=$ adsorption capacity, $\mathrm{g} / \mathrm{m}^{3}$.

$\mathrm{k}_{\mathrm{d}}=$ coefficient in the Freundlich adsorption isotherm.

$\mathrm{n}=$ coefficient in the Freundlich adsorption isotherm.

$\mathrm{A}=\mathrm{sN}_{0}+\mathrm{c}_{0}$. 